\title{
Insulin or Insulin-Like Studies on Unicellular Organisms: a Review
}

\author{
Alzira Martins Ferreira de Souza ${ }^{1 *}$ and Jorge A. López ${ }^{2}$ \\ ${ }^{I}$ Departamento de Bioquímica, CCB, Universidade Federal de Pernambuco, ex-Professor Av. Morais Rego, s/n \\ Cidade Universitária; 50670-420; Recife - PE - Brazil; ${ }^{2}$ Departamento de Parasitologia; ICB 2; Universidade de \\ São Paulo; 05508-900; São Paulo - SP - Brazil; e-mail: jalr@icb.usp.br
}

\begin{abstract}
This paper presents a review of studies about insulin and insulin-like substances in prokaryotes, eukaryotes and fungi have been published over the last two decades, constituting an updating of our previous review (1988) which included references to invertebrate insulin or insulin-like substances both in uni- and pluricellular Monera, Protoctista, Fungii and Animal species. This present article reviews experiments and evidence obtained using modern techniques in the understanding of molecule evolution and behaviour, which confirm its very ancient molecular structure origin. The involvement of insulin-like and related material in signalling biological pathway and modulator effects is also reported.
\end{abstract}

Key words: Unicellular, invertebrate, insulin, insulin-like, insulin receptor

\section{INTRODUCTION}

Since the 1970's investigations in the field of the comparative biochemistry have increased exponentially. Nowadays, investigators focus on the possible evolutionary ancestors of the insulin superfamily, e.g, insulins, insulin-related peptides, and the insulin-like growth factor. These peptides are not only present in vertebrates, as other related proteins have also been found in some unicellular organisms (Le Roith et al., 1980; Le Roith et al., 1981; Souza and López-Rodríguez, 1988; Lenard, 1992).

Insulin-like occurrence in invertebrates was identified with the clam tissues of Mya arenaria (Collip, 1923) as far back as eighty years ago. This present paper represents an updating of our previous review of studies on insulin in invertebrates (Souza and López-Rodríguez, 1988), aiming to include research on protist and prokaryote insulin or insulin-like substances carried out over the past two decades. In the current Biological Classification scheme these insulin-like substances correspond to prokaryotes, eukaryotes and fungi substances (Margulis, 1992). The review studies relieves the evolutionary origins of these insulin or insulin-like substances, and moves on to compare findings of metazoan insulin, or insulin-like substances and vertebrate insulin with respect to molecular structure, biological and immunological activities, and the technical difficulties of defining the molecular structure with the insufficient amount of material usually available.

*Author for correspondence 


\section{THE ORIGINS OF INSULIN MOLECULAR STRUCTURE}

The disclosure that insulin may have originated more than a billion years ago arose with the findings of Le Roith et al. (1980) which suggested that the molecular origins of insulin go at least as far back as the simplest univellular eukaryotes. Evidence of the presence of a substance with immunological and biological similarities to mammalian insulin in the bacterium Escherichia coli $K_{12}$ the year after (Le Roith et al., 1981), increased the possible time-span of its origins to two billion years.

\section{EVIDENCE OF INSULIN UNICELLULAR ORGANISMS}

In this updated review, the initial studies with prokayryote and eukaryote organisms from the decade of the 80's are reported, in particular the findings obtained from studies on the heterotrophic Protist protozoan species, (Monera and Protoctista Kingdom), which refer to the occurence of insulin-related molecules, their characterization and functionality in Monera and Protoctista species. From the Monera Kingdom the scientific literature presents references only from the bacterium Escherichia coli. The result obtained with $E$. coli $\mathrm{K}_{12}$ (Le Roith et al., 1981) cited above, was confirmed when Le Roith et al. (1985) worked with four more strains grown in defined medium. The extracts obtained were purified and the fractions submitted to immunoassay. The active material obtained was purified again with Sep-Pack $\left(\mathrm{C}_{18}\right)$ and Sephadex G-50 chromatography and applied to a DEAESephadex column. The immunoactive material was recovered as a peak, which overlaps the elution position of unlabelled and ${ }^{125}$ I-labelled porcine insulin and re-purified by HPLC. The purified material was found to have an immunoactivity to the anti-insulin antibody and similarity was demonstrated between the unicellular material and vertebrate insulins. More recently, Silva et al. (2002) utilizing modified ELISA and Western blotting methods demonstrated the presence of insulin-like antigens in extracts of the cyanobacterium Spirulina maxima (Monera Kingdom). In the scientific literature, studies have been published relating to
Tetrahymena among species belonging to the Protoctista Kingdom. Applying the flouresceinisothiocyanate (FICT)-insulin-binding technique to the detection of cellular membrane dynamics in the eukaryote Amoeba proteus, Köhidai et al. (1992) verified that 1) the number of insulin binding sites decrease in the control conditions as a function of time. The down regulation of binding sites lasts approximately $48 \mathrm{~h}$ and only low insulin concentration can induce a binding site elevation over the long term; 2) hormonal imprinting could be present in Amoeba. According to Le Roith et al. (1980), immunologically and biologically active insulin was found in ciliated protozoa Tetrahymena pyriformis extracts, grown in defined media in the absence of macromolecules. The extraction was proceeded according to a classical process (Mirsky, 1973), except that albumin was eliminated. The cells acid-ethanol extracts obtained from conditioned and unconditioned medium, where $T$. pyriformis has grown, were gelfiltered and the eluted material, using radioimmunoassay, was similar to the standard mammalian insulin. The conditioned medium eluate stimulated glucose incorporation into lipids when applied to rats, and its bioactivity was largely neutralized in the presence of anti-insulin antibody. Another study performed with another strain of the $T$. pyriformis extracts and with their culture medium extracts, purified on DEAEcellulose or DEAE-Sephadex and HPLC, was conducted submitting the material to immunoactivity assays. The results obtained showed a similar specific reaction to insulin in the immunoassay and bioassay for insulin as the previous, improving the probability that its insulin-like material may act as a signal (intra- or extracellular messenger signal) (Le Roith et al., 1985).

An autoradiographic study in Tetrahymena was conducted by Fulop and Csaba (1991), investigating the turnover and intranuclear localization of ${ }^{125}$ I-insulin. Cells were shown to have internalised the labelled insulin and the ${ }^{125}$ insulin had also entered the nucleus of Tetrahymena, where it was found in a heterochromatic localization. The insulinpretreated T. pyroformis retained a greater part of internalised insulin in the cytoplasm than the insulin non-pretreated cells. This retention decreased with additional exposure to excessive non-labelled insulin. Kovács and Csaba (1991) studied the micronucleus of normal and insulin 
pre-treated (imprinted) $T$. pyriformis and $T$. malaccensis under the effect of insulin treatment by using Feulgen reaction. They found a different reaction intensity; the duration of hydrolysis influenced the reaction. The experiments alert us to the possibility of the nuclear effect of hormonal imprinting. The bacitracin effect on $T$. pyriformis was also the aim of Kovács and Csaba (1992). Their experiments pointed out the role of insulin degradation in the insulin imprinting of these protozoa. Bacitracin was observed to inhibit the insulin imprinting and direct insulin binding, diminishing the glucose activated growth capacity and increasing lysosomal enzyme exocytosis. Several aspects of Tetrahymena insulin binding were observed in the same period, such as the results of Hegyesi and Csaba (1992a, 1992b) concerning the effect of pre-treatment (imprinting) using different concentrations of insulin on insulin binding of its nuclear envelope and plasma membrane, as well the specific insulin binding and the imprintability of the nuclear membrane. These authors verified that when treated with $10^{-6}-10^{-10}$ $\mathrm{M}$ insulin (imprinting), there was a down regulation both in the plasma membrane and in the nuclear envelope, corresponding to a decrease in the binding value related to the control. In the plasma membrane the power of binding was directly proportional to the increase of the hormone concentration used in the imprinting. For the nuclear envelope the optimal concentration was $10^{-8} \mathrm{M}$. At $10^{-10} \mathrm{M}$, the binding resulting imprinting was insignificant in the plasma membrane but it was still present in the nucleus (Hegyesi and Csaba, 1992a). Cellular nuclei which had been isolated from Tetrahymena were able to bind FITC-labelled insulin, and pre-treatment with different concentrations of unlabelled insulin accounted for a decrease in FITC-insulin binding of the nuclear envelope. Nuclei isolated one week after a primary exposure of cells to insulin showed a 50\% binding increase over the controls. This supports the implication that insulin imprinting also involves the receptors of the nuclear membrane of the imprinted cell (Hegyesi and Csaba, 1992b). The secreted peptides by Tetrahymena cells into inorganic medium were studied by Kovács et al. (1992b). Six peptide fractions, obtained by chromotography, showing enzyme-like activity were examined for influence on certain physiological parameters of Tetrahymena. They were seen to increase the phagocytic activity of the protozoa and decrease the binding capacity for lectins and for insulin, but to enhance insulin imprinting at primary interaction. Kovács et al. (1992a) also researched insulin binding and demonstrated that it was not influenced by Na-metavanadate. The ouabain effect prevented insulin imprinting when administered with insulin, but did not affect imprinting when administered after insulin administration. The results indicate that inhibition of $\mathrm{Na}^{+} \mathrm{K}^{+}$- ATPase plays no role in this insulinlike effect of vanadate on the unicellular Tetrahymena.

Other aspects of the Tetrahymena insulin binding have been investigated, with the following results: offspring generations of Tetrahymena pre-treated (imprinted) with insulin showed a greater binding capacity than that of untreated ones, according to Csaba and Kovács (1991). The epidermal growth factor imprinted for insulin to a greater degree than insulin itself, and vice-versa: insulin imprinted for EGF more efficiently than EGF itself. This can be explained by the overlap of insulin and EGF on one another receptors in Tetrahymena.

Christopher and Sundermann (1992) conducted experiments to verify the validity of the reports that $T$. pyriformis possesses binding structures for the vertebrate insulin that are amplified in cells having prior exposure to this hormone, and studies to localize the binding sites. Confocal microscopy of labelled RI cells with either fluorescein isothiocyanate-insulin or the immunocytochemical technique revealed labelling of the cytoplasm that appeared to be vesicular. Conventional fluorescence revealed ciliary labelling that could be decreased by incubation with excess unlabelled insulin.

Studies pursued by Csaba and Kovács (1995) on insulin treatment using $T$. pyriformis, revealed that, after about 200 generations, insulin levels significantly higher than the control had been detected by quantitative immuno-cytochemical method. The insulin content was always higher in the insulin-pre-treated (imprinting) cells than in the controls. The results emphasize the simultaneous stimulation of hormone and receptor formation by hormonal imprinting.

Some aspects of mammalian insulin effect on unicellular eukaryotes were processed using $T$. thermophyla. Christensen et al. (1998a) verified a prevention of a rapid cell death and/or promoted cell proliferation, a concentration-dependent effect. More recently, Leick et al. (2001) have 
extracted ciliary membrane proteins from isolated cilia of $T$. thermophyla, using affinity chromatography on columns fractionation with covalently bound fibroblast growth (FGF), insulin, or insulin concanavalin A, respectively. The eluted proteins were analysed using several techniques, including the use of specific antibodies against the insulinreceptor beta-subunit of human insulin receptor. According to Christensen et al. (1998b) who studied the dependence of insulin-mediated cell survival and proliferation in T. thermophyla, these depend on a protein kinase pathway, providing evidence for the tyrosine phosphorylation of a 66 $\mathrm{kDa}$ membrane protein.

Using radioimmunoassay and confocal laser scanning microscopy, Csaba et al. (1999) studied the immunological insulin-like material in Tetrahymena for 10 days after 4 or $24 \mathrm{~h}$ with $10^{-6}$ $M$ insulin treatment (imprinting). Confocal microscopy, using pig insulin antibody, localized insulin in the cell body. Insulin treatment (after 48 and 96h) caused an elevation of the insulin content in general and specific accumulation in the posterior cell sections, around the nucleus and in the periphery. Ten days after the treatments only the peripheral region of the cell body and ciliary row contained more insulin than the control. Insulin contained by Tetrahymena $48 \mathrm{~h}$ after imprinting, stimulated glucose uptake of rat diaphragm. Recent experiments with Tetrahymena using confocal microscopy support anterior observations in the study of insulin uptake and binding. During the first hour insulin imprinting treatment the process is slow. It accelerates $48 \mathrm{~h}$ after imprinting and $1 \mathrm{~min}$ after the second treatment starts, and then more insulin is present on the surface and inside the cells. Theoretically, this hormonal imprinting effect helps to maintain the species by facilitating molecular recognition and binding as well as uptake of useful molecules (Csaba and Kovacs, 2000).

\section{STUDIES WITH FUNGI (TRUE FUNGI)}

According to Le Roith et al. (1980) imumunologically and biologically active insulin was found in acid-ethanol extracts of the fungi Neurospora crassa and Aspergillus fumigatus grown in a simple defined medium. The extracts from A. fumigatus were gel-filtered and the eluates presented bioactivity three times its immunoreactivity, being partially neutralized $(35 \%)$ in the presence of anti-insulin antibody. N. crassa material obtained in the same manner presented identical bioactivity and it was $65 \%$ neutralized in the presence of the anti-insulin antibody. The authors conceded that the fungi material obtained was similar to purified mammalian insulins in its solubility in acid-ethanol, elution profile, bioactivity in bioassay systems, and the neutralization of its bioactivity by anti-insulin antibody.

The findings from Thim et al. (1986) showed a series of dibasic insulin precursors including proinsulin expressed and secreted by the fungi Saccharomyces cerevisiae. Recombinant plasmids were constructed to encode fusion proteins consisting of a modified mating factor alpha leader sequence and an insulin precursor. The purified secreted peptides (from fermentation broth) were characterized by sequencing and aminoacid analysis. Processing at one or both dibasic sequences was shown in proinsulin and in other insulin precursors containing a short spacer peptide in the place of the C-peptide, considered indispensable to processing. Specific effects of human insulin on oxidative and non-oxidative glucose metabolism in yeast were also observed (Müller, 2000).

Silva et al. (2002) showed insulin-like antigens in extracts of Saccharomyces cerevisiae at the same position as bovine insulin on a Western blots band.

\section{STUDIES IN UNICELLULAR INSULIN- LIKE RECEPTORS}

Interest has increased in insulin or insulin-like binding mechanisms with the development of improved specific techniques based on the idea of Le Roith et al. (1980) that unicellular related material may act as an intercellular signal. The first findings were obtained with fungi. Cells of the wall-less (slime) of $N$. crassa were studied by Fawell and Lenard (1988), verifying the specific high affinity insulin-binding sites on their surface and the cell displacement of ${ }^{125}$ I-labelled bound insulin occurred (weakly) only with IGF-I and proinsulin.

Research from the decade of the 90's aimed to elucidate the unicellular insulin-like binding site mechanisms, preponderantly using the fungi $N$. crassa and $S$. cerevisiae, and the protozoan Tetrahymena (Monera and Protoctista Kingdom species). Kole et al. (1991) have purified to 
homogeneity a membrane-bound insulin binding protein of $N$. crassa presenting $66 \mathrm{kDa}$. They asserted that this protein could be the "receptor" that mediates insulin-induced downstream metabolic effects.

Angermayr et al. (2000) described the stable expression of the complete cytoplasmic protein fragment of hInsR including the juxtamembrane domain in yeast cells, with an apparent molecular mass of $48 \mathrm{kDa}$, and autophosphorylation capacity. They found that this autophosphorylation occured in tyrosine residues and that the tyrosine kinase activity did not interfere with glucose signalling in yeast. The absence of a substrate protein IRS-1-4 homologue which mediates most responses to insulin in mammals is probable. The results show that in yeast the interaction with hInsR apparently fails. The authors concluded that possibly a coexpression of the kinase domain of hInsR and IRS1 is required for functional coupling of the former to glucose signalling cascade in yeast.

According to Müller (2000), a $53 \mathrm{kDa}$ plasma membrane protein has been identified in S. cerevisiae, which specifically binds human insulin, with Kdvalues of 0.3 to $0.7 \mu \mathrm{M}$. It undergoes phosphorylation in response to insulin on serine residues exclusively. This author claims that the yeast insulin-binding protein differs from the putative receptor from $N$. crassa and from the mammalian insulin receptor. The literature presents others unicellular organism insulinlike receptor research with the protozoan species Tetrahymena and A. proteus. Beyond the Mychota specie studies, the literature presents other unicellular organism insulin-like receptor research with Protoctista species.

Köhidai et al. (1992) developed a new technique for evaluation of cell membrane dynamics. Insulin binding sites of $A$. proteus were analysed and the authors verified that hormonal imprinting could be present. Others receptor studies were undertaken with the ciliated protozoan Tetrahymena. The findings from Hegyesi and Csaba (1992a) with Tetrahymena provided support for the interpretation that insulin imprinting also involves the receptors of imprinted cell plasma membrane and also of nuclear envelope. A 50\% binding decrease over controls was observed with isolated cellular nuclei one week after primary exposure of Tetahymena cells to insulin. This supported the thesis of Hegyesi and Csaba (1992b) that hormonal (insulin) imprinting involves imprinted cell nuclear membrane receptors. The same authors studying the effect of permanent starvation on the nuclear envelope insulin receptors following a $2 \mathrm{~h}$ starvation (one cell generation) observed that Tetrahymena insulin receptors can bind the insulin similarly to the fed, control cells and the nuclear envelope cells can bind even more strongly. This binding capacity decreases after $18 \mathrm{~h}$ starvation. It is probable that the insulin receptors of Tetrahymena plasma membrane and nuclear envelope are identical. (Hegyesi and Csaba, 1994). Studies with $T$. pyriformis were conducted by Christopher and Sundermann (1992) using conventional and confocal microscopy to localize the binding sites and insulin receptors induction. The results confirm the binding capacity for insulin and that the prior insulin exposure increase action is proportionate to the concentration of insulin used. Further studies with the exomutant of $T$. thermophyla SB255 showed that mucocyst discharge and capsule formation are not involved in insulin binding. A Tetrahymena pyriformis ciliary membrane protein $(62-67 \mathrm{kDa})$ immunologically similar to porcine insulin was isolated by Christopher and Sundermann (1995). This insulin-like protein may function as precursor to the soluble form and as a membrane-bound binding site/receptor. An antibody correspondent to the human insulin receptor alpha-subunit peptide was used by Christopher and Sundermann (1996) to investigate the localization and the partial characterization of immunoreactive proteins in insulin- and non-insulin exposed cells of T. pyriformis. Confocal and immunoelectron microscopy, PAGE and immunobloting techniques were used in this study. Immunoblotting revealed two reactive proteins in whole cell lysates but none in ciliary membrane extracts or eluates. Based on these findings, it seems unlikely that a cell surface structure similar to mammalian insulin receptor exists in T. pyriformis.

More recently, Leick et al. (2001) extracted the ciliary membrane protein from isolated cilia of $T$. thermophyla. The extract was fractionated and analysed. A 66kDa protein eluted fraction reacted in Western immunoblots to an antibody against the beta-subunit of the human insulin receptor. This fraction analysed by SDS-PAGE appeared as a single component with $\mathrm{pI}$ of 7.3.

The possible role of this $66 \mathrm{kDa}$ glycoprotein was acknowledged as the protein involved in peptidemediated cell signalling. The unicellular insulinlike occurrence and characterization references are summarized in the table 1 . 
Table 1. References of insulin and insulin-like substances occurrence in Protoctista, Monera and Mychota species

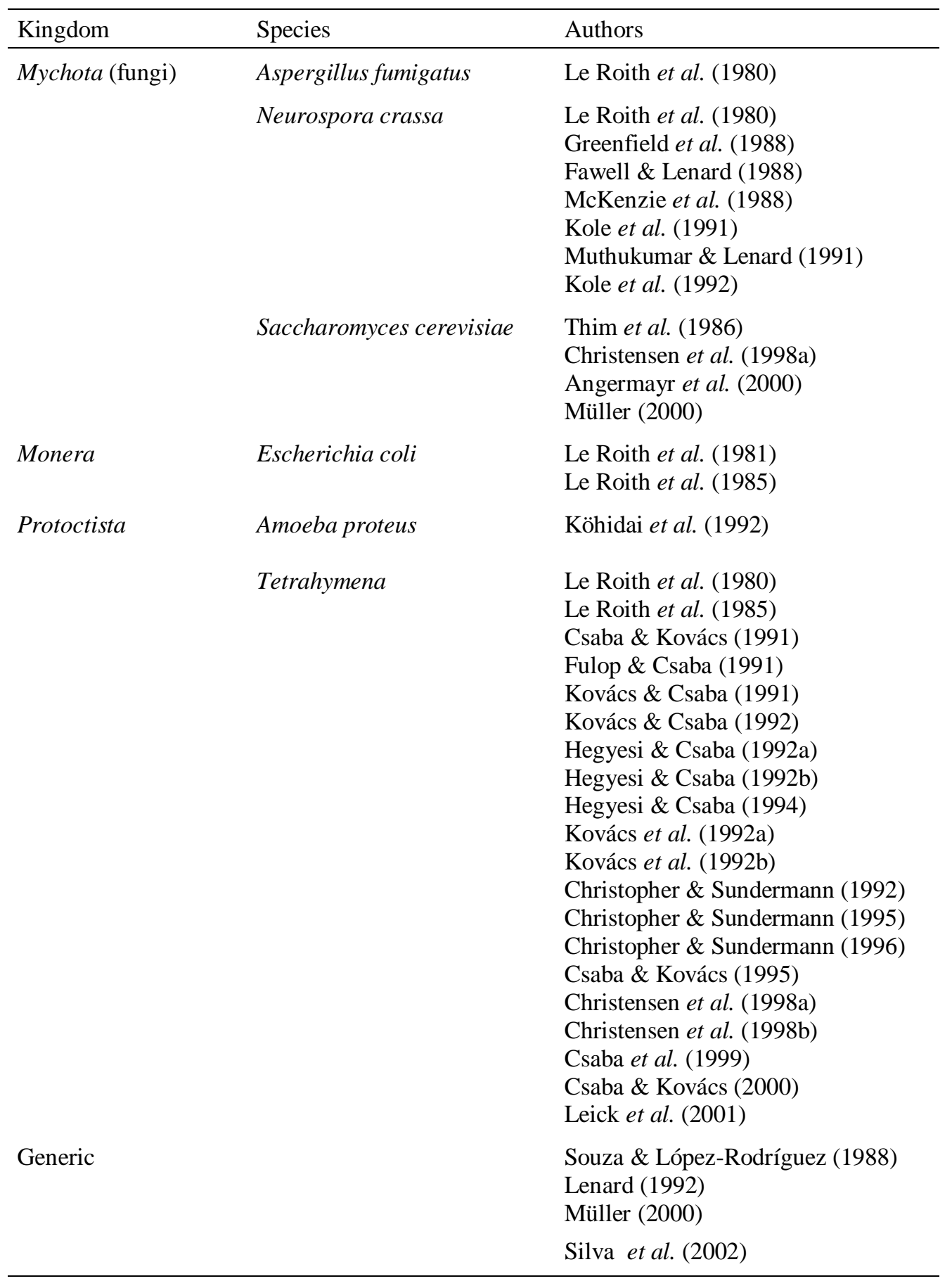

\section{DISCUSSION}

Our previous review (Souza and López-Rodríguez, 1988) of Invertebrate Insulin studies surveyed studies published between 1973 to 1987 on the occurrence and characterization of insulin or insulin-like substances in uni-and pluricellular invertebrate organisms prokaryotes, eukaryotes, and fungi (Monera, Protoctista, Michota and Animal Kingdom), discussing the methodology employed and the results. These findings suggested the phylogeneticaly ancient origin of the insulin molecular structure.

This present review includes references only to unicellular organism insulin or insulin-like studies, as current publication practice favours the separate 
review of uni-and pluricellular organisms insulin studies. The focus since 1987 has been on the insulin-like role action mechanism, based on the suggestion of Le Roith et al. (1980, 1981), that this molecular structure may be of a very ancient origin.

Besides the studies relating to fungi covered in this paper, other correlated aspects have been studied. Due to the lack of adequate amounts of purified insulin or insulin-like required for the techniques, the molecular structure can not be known, but its evidence provoked enough interest to verify its effects on the cells themselves or on typical insulin target cells. The results of McKenzie et al. (1988) suggest that all differentiated insulin have arisen from conserved insulin genes in unicellular organisms. The isolation of a preproinsulin-like pseudogene from the genome of $N$. crassa by PCR (Muthukumar and Lenard, 1991) supports the molecular evolutionary proposal, and the characterization of a thiol-dependent proteinase resembling insulinase (Kole et al., 1992), also from $N$. crassa, allows us to extent this apparent evolutionary conservation to specific proteases. Greenfield et al. (1988) have observed that the substance detected in this fungi, which somehow resembles mammalian insulin, exerts metabolic effect in mammalian adypocites.

The insulin precursor expression and secretion, including proinsulin, was found in S. cerevisiae by Thim et al. (1986). According to Lenard (1992) hormones and hormones binding proteins resembling those of vertebrates are widespread in fungi, yeast and bacteria, and functional responses of microbial cells to mamaliam hormone have been found. Aspects of inter- and intracellular signaling systems in cell survival, proliferation, differentiation, chemosensory behaviour, and programmed cell death in free-living unicellular organisms have been observed in S. cerevisiae and Tetrahymena by Christensen et al. (1998a). Angermayr et al. (2000) suggested a failure of the active insulin receptor kinase domain in coupling to yeast (glucose) signaling cascades. Intracellular systems present many common features in uniand multicellular organisms, like the physiological responses obtained in studies using the yeast Schizosaccharomyces pombe that provide evidence for a insulin signaling pathway (Buckley et al., 2002). This fungi can be used to analyse the tyrosine kinase activity of the IGF-1 R beta chain and its regulation by tyrosine kinase phosphatases. Aiming to clarify the mechanisms of insulin-like binding sites using principally the fungi $N$. crassa and $S$. cerevisiae, and the protozoan Tetratrahymena, Kole et al (1992) purified a membrane bound insulin binding protein of $N$. crassa cells, which possesses $66 \mathrm{kDa}$ and $\mathrm{pI} 7.4$. They suggested this to be the "receptor" that mediates insulin-induced downstream metabolic effects. In addition to the fungi studies, the Protoctist species Amoeba proteus and Tetrahymena insulin binding sites were also targetted for research.

Kohidai et al. (1992) have analyzed the insulin binding sites in $A$. proteus, verifying its number variegation according to insulin concentrations.

Christopher and Sundermann (1995) have isolated and partially characterized the ciliary membrane binding sites for insulin from $T$. pyriformis The ciliary membrane binding sites are immunologically similar to insulin and present 62$67 \mathrm{kDa}$. The authors hypothesized that it may function as both precursor to a soluble form and membrane-bound binding site/receptor. After that, the research conducted on $T$. thermophyla by Christensen et al. (1998b) demonstrated that insulin-mediated cell survival and proliferation are protein-kinase pathway dependent and the evidence for the $65 \mathrm{kDa}$ membrane protein tyrosine phosphorylation. Recently, Leick et al. (2001) indicated that the $66 \mathrm{kDa}$ glycoprotein form T. thermophyla ciliary membrane may have a role in peptide mediated cell signaling. These findings suggest that membrane insulin-like binding sites have similar aspects when studied with $T$. pyriformis, $T$. thermophyla and $N$. crassa (Protoctista and Mychota Kingdom).

Recently, studies seeking to understand the yeast molecular mechanisms that mediate life span extension have been published. There are studies on yeast and other organisms implicating similar proteins in the regulation of longevity. Longo and Fabrizio (2002) reported yeast mutations which decrease the glucose activity signaling pathways, extending longevity by activating stress resistance transcription factors that regulate the expression of genes involved in antioxidant and heat protection, glycogen storage, protein degradation, DNA repair and metabolism. The studies indicate that glucose or insulin/IGF-1 may act on directly down regulating stress resistance genes as occur in mammalian cells. Given the similarities among longevity regulatory pathways in different organisms (from yeast to mice), the authors suggest that insulin/IGF-1 signalling pathways 
may regulate cell damage and longevity in humans. According to Yamaza et al (2002), the life-prolonging effect of caloric restriction requires NPT1 and S1R2 genes in lower organisms such as yeast. Longo and Finch (2003) published a review which indicated that yeast mutations in glucose or IGF-1-like signaling pathways extend life-span but also cause glycogen accumulation. They suggested that the similarities in longevity regulatory pathways between yeast and invertebrate organisms must occur because some portions of these pathways have evolved from a common ancester. Warner (2003) published the information that the National Institute of Aging (NIA) has started a program to identify genes involved in longevity regulation, including in yeast.

\section{RESUMO}

Esta atualização de nossa publicação prévia de revisão sobre insulina em invertebrados, referencia exclusivamente as publicações dos últimos quinze anos sobre insulina e/ou insulina-símile em organismos unicelulares dos reinos Monera, Protoctista e Mychota, desde que o número de publicações justifica o procedimento de atualização da revisão de organismos uni- e pluricelulares separadamente. Reúne os dados obtidos na tentativa de esclarecer a origem filogenética da substância e a funcionalidade. As referências se reportam à ocorrência da molécula, suas características de reatividade e aspectos dos receptores de insulina ou insulina-símile em unicelulares.

\section{REFERENCES}

Angermayr, M.; Stroble, G.; Müller, G. and Banlow, W. (2000), Stable plasma membrane expression of the soluble domain of the human insulin receptor in yeast. FEBS Lett., 481, 8-12.

Buckley D.A.; Loughran, G.; Murphy, G.; Fennelly, C. and O'Connor R. (2002), Identification of an IGF-1R kinase regulatory phosphatase using the fission yeast Schizosaccharomyces pombe and a GFP tagged IGF-IR in mammalian cells. J. Clin. Mol. Pathol., 55, 46-54.

Christensen S. T.; Leick, V.; Rasmussen, L. and Wheatley, D. N. (1998a), Signalling in unicellular eukaryotes. Int. Rev. Cytol., 177, 181-253.
Christensen, S. T.; Neve, S.; Kristiansen, K. and Leick, V. (1998b), Insulin mediated cell survival and proliferation in the unicellular eukaryote Tetrahymena thermophyla depend on the protein kinase pathway. Evidence for the tyrosine phosphorylation of a $65 \mathrm{kDa}$ membrane protein. Mol. Biol. Cell., 9 : (Suppl. S), 664.

Christopher, G. K and Sundermann, C. A. (1992), Conventional and confocal microscopic studies of insulin on insulin receptor induction in Tetrahymena pyriformis. Exper. Cell Res. Int., 201, 477-484.

Christopher, G. K. and Sundermann, C. A. (1996), Intracellular insulin binding in Tetrahymena pyriformis. Tissue Cell., 28, 427-437.

Christopher, G. K. and Sundermann, C. A. (1995), Isolation and partial characterisation of the insulin binding sites of Tetrahymena pyriformis. Biochem. Biophys. Res. Comm., 212, 515-523.

Collip, I. B. (1923), The demonstration of an insulinlike substance in the tissues of the clam (Mya arenaria). J. Biol. Chem., 55, 39.

Csaba, G.; Gaal, A.; Kovács, P.; Simon, G. and Köhidai, L. (1999), Prolonged elevation of insulin content in the unicellular Tetrahymena after insulin treatment induction of insulin production or storage? Cell Biochem. Funct., 17, 165-173.

Csaba, G. and Kovács, P. (1991), EGF receptor induction and insulin - EGF overlap in Tetrahymena. Experientia, 47, 718-721.

Csaba, G. and Kovács, P. (1995), Insulin treatment (hormonal imprinting) increases the insulin production of the unicellular Tetrahymena long term. Is there a simultaneous formation of hormone receptor and hormone? Cell Biol. Int., 19, 1011-1014.

Csaba, G. and Kovács, P. (2000), Insulin uptake, localization and production in previously insulin treated and untreated Tetrahymena. Data on the mechanism of hormonal imprinting. Cell Biol. Int., 18, 161-167.

Fawell, S. E. and Lenard, R. D. J. (1988), A specific insulin receptor and tyrosine kinase activity in membrane of Neurospora crassa. Biochem. Biophys. Res. Commun., 155, 59-65.

Fulop, A. K. and Csaba, G. (1991), Turnover and intranuclear localization of iodine-125 insulin in Tetrahymena: an autoradiographic study. Acta Morphol. Hung., 39, 71-78.

Greenfield N. J.; McKenzie, M. A.; Adebodun, F.; Jordan, F. and Lenard, J. (1988), Metabolism of D-glucose in a wall-less mutant of Neurospora crassa examined by $\mathrm{C}-13$ and $\mathrm{P}-31$ nuclear magnetic resonances - effects of insulin Biochem., 27, 8526-8533.

Hegyesi, H. and Csaba, G. (1992a), Effect of pretreatment (imprinting) with different 
concentrations of insulin on insulin binding of nuclear envelope and plasma membrane in Tetrahymena. Cytobios, 72, 191-196.

Hegyesi, H. and Csaba, G. (1992b), Specific insulin binding by, and imprintability of the nuclear membrane or Tetrahymena. Cytobios, 72, 153-157.

Hegyesi, H. and Csaba, G. (1994), Effect of permanent starvation on the insulin receptors of the nuclear envelope of Tetrahymena. Acta Microbiol. Immunol. Hung., 41, 241-245.

Köhidai, L.; Kihara, A. and Csaba, G. (1992), Correlation of insulin pretreatment and insulin binding of Amoeba proteus: a new technique for evaluation. Comp. Biochem. Physiol. A, 103, 535-539.

Kole, H. K.; Muthukumar, G. and Lenard, J. (1991), Purification and properties of a membrane-bound insulin binding protein, a putative receptor, from Neurospora crassa. Biochem., 30, 682-688.

Kole, H. K., Smith, D. R. and Lenard, J. (1992), Characterization and partial purification of an insulinase from Neurospora crassa. Arch. Biochem. Biophys., 297, 199-204.

Kovács, P. and Csaba, G. (1992), Effect of bacitracin on Tetrahymena: Acta Protozool., 31, 241-246.

Kovács, P. and Csaba, G. (1991), Impact of hormonal imprinting on the hydrolysis time of the Fuelgen reaction in Tetrahymena: do nuclear level changes appear after imprinting? Acta Protozool., 30, 107-114.

Kovács, P.; Hegyesi, H. and Csaba, G. (1992a), Effect of vanadate and ouabain on insulin binding and insulin imprinting in Tetrahymena. Cell Biochem. Funct., 10, 31-34.

Kovács, P.; Karsa, J. and Csaba, G. (1992b), Studies into secretion of Tetrahymena: Enzymes secreted into organic medium. Microbios, 70, 57-65.

Leick, V.; Bog-Hansen, T. C. and Juhl, H. A. (2001), Insulin/FGF-binding ciliary membrane glycoprotein from Tetrahymena. J. Mem. Biol., 181, 47-53.

Lenard, J. (1992), Mammalian hormones in microbial cells. TIBS, 17, 147-150.

Le Roith, D.; Shiloach, J.; Heffron, R.; Rubinovitz, C.; Tanenbaum, R. and Roth, J. (1985), Insulin-related material in microbes: similarities and differences from mammalian insulins. Can. J. Biochem. Cell Biol., 63, 839-849.

Le Roith, D.; Shiloach, J; Roth, J. and Lesniak, M. A. (1980), Evolutionary origins of vertebrate hormones: substances similar to mammalian insulin are native to unicellular eukaryotes. Proc. Natl. Acad. Sci. USA, 77, 6184-6188.

Le Roith, D.; Shiloach, J; Roth, J. and Lesniak, M. A. (1981), Insulin on a closely related molecule is native to Escherichia coli. J. Biol. Chem., 256, 6533-6536.

Longo, V. D. and Fabrizio, P. (2002), Regulation of longevity and stress resistance: a molecular strategy conserved from yeast to humans? Cell Mol. Life Sc., 59, 903-908.
Longo, V. D. and Finch, C.E. (2003), Evolutionary medicine: from dwarf model systems to healthy centenarians? Science, 299, 1342-1345.

Margulis, L. (1992), Biodiversity: molecular biological domains, symbiosis and kingdom origins. Biosystems, 27, 39-51.

McKenzie, M. A; Fawell, S.A.; Cha, M. and Lenard, J. (1988), Effects of mammalian insulin on metabolism, growth and morphology of a wall-less strain of Neurospora crassa. Endocrinol., 122, 511-517.

Mirsky, I. A. (1973). In: Berson, S. A. (Ed.). Methods in investigative and diagnostic endocrinology. New York : American Elsevier. pp. 823-883.

Müller, G. (2000), Insulin-like and insulin-mimetic molecules and signalling in lower Eucaryontes. Recent Res. Devel. Endocrinol., 1, 1-36.

Muthukumar, G. and Lenard, J. (1991), A preproinsulin-like pseudogene from Neurospora crassa. Mol. Cell Endocrinol. , 82, 275-283.

Silva L.B.; Santos, S. S. S.; Azevedo, C. R.; Cruz, M. A. L.; Venâncio, T. M.; Cavalcante, C. P.; Uchoa, A. F.; Astolfi Filho, S.; Oliveira, A. B. A.; Fernandes, K. V. S. and Xavier-Filho, J. (2002), The leaves of green plants as well as a cyanobacterium, a red alga, and fungi contain insulin-like antigens. Braz. J. Méd. Biol. Res., 35, 297-303.

Souza, A. M. F. and López-Rodríguez, J. A. (1988), Insulina em invertebrados. Ciência e Cultura, 40, 9324-328.

Thim, L.; Hansen, M. T.; Norris, K.; Hoegh, I.; Boel, E.; Forstrom, J.; Ammerer, G. and Fiil, N. P. (1986), Secretion and processing of insulin precursor in yeast. Proc. Natl. Acad. Sci. USA, 83, 6766-6770.

Warner, H. R. (2003), Subfiel history: use of model organisms in the search for human aging genes, $S c i$ Aging Knowl. Environ., 12, RE1.

Yamaza, H.; Chiba, T.; Higami, Y. and Shimokawa, I. (2002), Lifespan extension by caloric restriction: an aspect of energy metabolism. Microsc. Res. Tech., 59, 325-330.

Received: November 11, 2002; Revised: August 18, 2003; Accepted: May 18, 2004. 